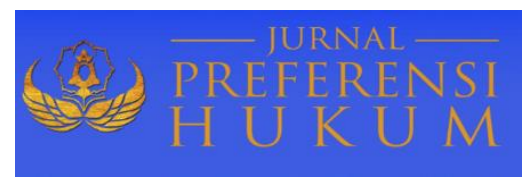

Jurnal Preferensi Hukum | ISSN: XXXX | E-ISSN: XXXX

Vol. 1 No. 1 - Juli 2020 hal. 8-13| Available online at https://www.ejournal.warmadewa.ac.id/index.php/juprehum

\title{
PELAKSANAAN INVESTASI DALAM PENGEMBANGAN KAWASAN BUDIDAYA PERTANIAN DI KABUPATEN BULELENG
}

\author{
I Gusti Made Ngurah Bagus Andre Wedananta, I Nyoman Putu Budiartha, Putu Ayu Sriasih Wesna \\ Fakultas Hukum Universitas Warmadewa, Denpasar - Bali, Indonesia
}

\begin{abstract}
Abstrak
Salah satu daerah yang tengah melaksanakan pembangunan di Indonesia ialah Kabupaten Buleleng Provinsi Bali. Pembangunan daerah ini dititikberatkan pada pengembangan bidang ekonomi dengan prioritas yaitu pada pembangunan sektor pertanian dalam arti luas yang ditunjang oleh pembangunan sektor pariwisata. Salah satu bagian dari pembangunan sektor pertanian tersebut adalah pengembangan kawasan budidaya pertanian dalam arti luas dengan dukungan dana yang berasal dari penanaman modal. Sayangnya, pada kenyataan, pengembangan kawasan budidaya pertanian tersebut terlihat belum berjalan seperti yang diharapkan. Kajian ini mengalamatkan dua permasalahan terkait pembangunan ini. Yang pertama ialah terkait dengan apakah perangkat peraturan perundang-undangan yang mengatur sektor pembangunan sudah cukup mampu menarik minat para investor dalam upaya mengembangkan kawasan budidaya pertanian di kawasan Kabupaten Buleleng, dan yang kedua ialah terkait dengan sejauhmana proses pelaksanaan dan pembangunan kawasan budidaya pertanian di Kabupaten Buleleng serta hambatan yang dihadapi. Untuk mencapai tujuan-tujuan ini, kajian ini dilakukan menggunakan desain dan metode penelitian normatif dan penelitian hukum empiris dan juga menggunakan pendekatan perundang-undangan serta pendekatan konseptual. Hasil analisis data menunjukkan perangkat peraturan perundang-undangan mempunyai power cukup untuk menunjang pengembangan kawasan budidaya pertanian di Kabupaten Buleleng, dan pelaksanaan pembangunan kawasan pertanian dalam arti luas sudah dilaksanakan, dan bahkan hasilnya sudah dirasakan dan dinikmati masyarakat. Salah satu faktor hambatan yang ditemukan ialah terjadinya alih fungsi lahan seiring evolusi dan revolusi dalam hidup manusia. Perhatian dan campur tangan berbagai pihak dalam upaya pembangunan dan pengembangan kawasan di Kabupaten Buleleng masih sangat diperlukan.
\end{abstract}

Kata Kunci: Budidaya Pertanian; Kawasan; Pengembangan; Penanaman Modal

\begin{abstract}
One area carrying out development in Indonesia is Buleleng Sub-district in the Province of Bali. The development of the region is merely focused on developing the economic sector with priority on the agricultural sector expansion in a broad sense which is supported by the development of the tourism sector. One part of the agricultural sector development is the agricultural cultivation areas in the broadest sense with the support of funds from investment. Unfortunately, in reality, the development of this cultivation does not seem to have proceeded as expected. Therefore, this study addresses two issues related to this development. The first is whether or not the laws and regulations governing the development have been sufficiently capable of attracting the interest of investors in efforts to develop agricultural cultivation areas in the region of Buleleng, and the second is the extent to which the process of implementation of the development of agricultural area cultivation in Buleleng area has reached as well as obstacles encountered. To achieve these objectives, this study was conducted using the design and method of normative research and empirical legal research and also used statutory and conceptual approaches. The results of show the set of laws and regulations have the sufficient power to support the development of agricultural cultivation in the area, and the implementation of agricultural development in a broad sense has been carried out, and even the results have been felt and enjoyed by the community. One leading obstacle factor found is conversion of land functions along with evolution and revolution in human life. The attention and intervention of various parties in the efforts to develop and extend the areas in Buleleng Sub-district is still crucially necessary.
\end{abstract}

Keywords: Agricultural Cultivation; Region; Development; Investment 


\section{PENDAHULUAN}

Mewujudkan tujuan nasional dapat dilaksanakan melalui pembangunan di segala bidang kehidupan yang dilangsungkan secara berkelanjutan. Untuk mencapai tujuan tersebut, dalam UU No. 10 Tahun 1998 tentang Perbankan dalam penjelasan umum dinyatakan bahwa dalam pelaksanaan pembangunan tersebut senantiasa harus memperhatikan keserasian serta peningkatan di bidang ekonomi dan keuangan. Dalam upaya peningkatan ekonomi, perlu adanya suatu program yang dapat meningkatan taraf hidup masyarakat (Tulusan \& Londa, 2014; Ciolac et al., 2019; Beeton, 2006), salah satu dari program tersebut adalah sektor pertanian dalam arti luas, mengingat masyarakat Indonesia adalah masyarakat agraris, seperti tercantum dalam Klausul Menimbang UU No. 5 Tahun 1960 tentang Peraturan Dasar Pokok-Pokok Agraria huruf a yang menyatakan "bahwa di dalam Negara Republik Indonesia yang susunan kehidupan rakyatnya, termasuk perekonomiannya, terutama masih bercorak agraris..."

Provinsi Bali, sebagai daerah otonom yang berada dalam wilayah Negara Kesatuan Republik Indonesia (NKRI), merupakan salah satu provinsi yang sedang giat melaksanakan pembangunan di segala bidang dkk., 2019), yang dititikberatkan pada pembangunan di bidang ekonomi dengan prioritas pada Pembangunan Sektor Pertanian dalam arti luas dan Sektor Pariwisata. Pelaksanaan pembangunan Provinsi Bali mengacu pada Rencana Pembangunan Jangka Panjang Daerah yang diatur dalam PERDA No. 6 Tahun 2009 tentang Rencana Pembangunan Jangka Panjang Daerah (RPJPD) Provinsi Bali Tahun 2005 - 2025, dibagi menjadi 4 (empat) wilayah pembangunan (WP), yaitu; 1) Wilayah Pembangunan Bali Timur (WPBT) meliputi Kabupaten-kabupaten Karangasem, Klungkung dan Bangli; 2) Wilayah Pembangunan Bali Selatan (WPBS) meliputi Kota Denpasar, Kabupaten-kabupaten Badung, Gianyar dan Tabanan; 3) Wilayah Pembangunan Bali Utara (WPBU) meliputi Kabupaten Buleleng; dan 4) Wilayah Pembangunan Bali Barat (WPBB) meliputi Kabupaten Jembrana. Adanya ketimpangan kemajuan antar wilayah dalam kemajuan pembangunan yang sedang dilaksanakan dikarenakan WPBS merupakan wilayah yang jauh lebih berkembang dibandingkan dengan Wilayah Pembangunan (WP) lain. WPBS dari sisi perkotaan merupakan penyumbang terbesar Pendapatan Daerah Regional Bruto (PDRB) yakni sebesar 67 \% (Kantor Perwakilan Bank Indonesia Provinsi Bali, 2019; Kementerian PPN/Bappenas, 2018).

Demikian juga dalam hal penanaman modal dewasa ini, kegiatan pembangunan terutama yang dibiayai dari penanam modal, investasi baik PMDN (Penanam Modal dalam Negeri) maupun PMA (Penanam Modal Asing), lebih banyak berlokasi di WPBS. Amino investor lebih banyak investasi di WPBS terutama Kota Denpasar, Kabupaten Badung, dan Kabupaten Gianyar (Yudyawati \& Koman, 2015). Sedangkan pemerintah daerah menginginkan adanya keseimbangan pembangunan di seluruh wilayah Bali, termasuk dalam menerima investasi baik dari PMDN maupun PMA.

Kabupaten Buleleng merupakan salah satu kabupaten yang sektor pembangunannya bersumber dari dana investasi yang tidak sesuai dengan harapan (BAPPEDA Buleleng, 2015; Kantor Perwakilan Bank Indonesia Provinsi Bali, 2019). Kajian dalam tulisan ini menekankan pada pembangunan sektor pertanian sebagai salah satu sektor penting yang perlu terus dikembangkan sebagai wilayah yang terluas di Provinsi Bali dengan potensi pertanian yang beraneka ragam, namun masih perlu ditingkatkan. Peningkatan sektor pertanian ini masih mengalami banyak kendala, di antaranya ialah dalam hal pembiayaan. Sehingga diperlukan adanya sumber pembiayaan terutama yang berasal dari penanam modal (investasi) baik PMDN maupun PMA.

Kabupaten Buleleng memiliki potensi pertanian dalam arti luas dan pariwisata yang potensial, namun potensi tersebut belum dapat dikembangkan secara maksimal karena dana investasi sebagai sumber pembiayaan yang menjadi kendala hingga saat ini (Beeton, 2006). Selama dasa warsa ini sektor pertanian dalam arti luas seperi pertanian tanaman pangan, perkebunan, perternakan, dan perikanan, termasuk juga sektor pariwisata masih di danai atau dananya diperoleh dari masyarakat. Suatu kawasan dibutuhkan untuk mewujudkan tercapainya sektor pertanian yang maju dan tangguh (Praktiknya, 2007), sebagai tempat pemusatan kegiatan pertanian yang dilengkapi dengan sarana dan prasarana penunjang yang dikembangkan oleh perusahaan yang mengelola pertanian yang memiliki izin yang diprasyaratkan. Berdasarkan atas ketentuan UU No. 23 Tahun 2014 tentang Pemerintahan Daerah dengan berlakunya otonomi daerah pemerintah daerah dapat mengambil langkah-langkah yang memungkinkan lokasi-lokasi yang menjadi objek pengembangan wilayah pertanian dapat dialokasikan dari dana investasi.

Atas dasar latar belakang di atas, kajain ini menelaah dua jenis masalah: 1) Apakah perangkat peraturan perundang-undangan sudah efektif untuk pengembangan budidaya pertanian dalam menarik 
minat investor di Kabupaten Buleleng? 2) Bagaimana hambatan pelaksanaan investasi dalam pembangunan kawasan budidaya pertanian di Kabupaten Buleleng. Setiap kegiatan sudah tentu memiliki tujuan yang ingin di capai, demikian juga penelitian ini memiliki tujuan yang ingin di capai untuk mengetahui perangkat peraturan perundang-undang dalam melaksanakan pengembangan kawasan budidaya pertanian di Kabupaten Buleleng dan untuk mengetahui pelaksanaan dan pembangunan kawasan budidaya di wilayah tersebut.

\section{METODE PENELITIAN}

\section{Tipe Penelitian}

Jenis metode yang digunakan dalam penelitian ini adalah penelitian hukum empiris, yaitu dengan melaksanakan pengkajiannya berdasarkan bahan-bahan hukum dari literatur dan merupakan suatu proses untuk menemukan aturan hukum, prinsip-prinsip hukum, dan juga ketetapan hukum dalam pelaksanaa pengembangan kawasan budidaya pertanian menggunakan modal yang bersumber dari penanam modal.

\section{Sumber Data}

Data primer adalah data yang diperoleh dari penelitian lapangan. Sedangkan yang dimaksud data sekunder adalah data yang diperoleh dari bahan hukum primer yang bersumber dari peraturan perundangundangan dan dokumen hukum, dan data yang bersumber pada bahan hukum sekunder terdiri dari bukubuku ilmiah dan tulisan-tulisan hukum (Yudyawati \& Koman, 2015).

1. Data Primer

Bahan hukum primer adalah data yang bersumber dari penelitian lapangan yaitu suatu data yang diperoleh langsung dari sumber pertama di lapangan baik dari responden maupun informan (Pedoman Penulisan Usulan Penelitian Tesis Program Studi Megister Hukum Universitas Udayana:39). Data primer ini diperoleh dari hasil wawancara dengan informan.

2. Data Sekunder

Data sekunder adalah data yang dihimpun peneliti dari kepustakaan (library reseach). Data sekunder terdiri dari bahan hukum primer berupa UUD 1945, KUH Prdt, UU No. 5 Tahun 1960, UU No. 25 Tahun 2007, UU No.23 Tahun 2014. Bahan hukum sekunder berupa literatur terkait masalah yang diteliti.

\section{Teknik Pengumpulan Data}

Teknik pengumpulan data primer dilakukan dengan cara studi lapangan yaitu dengan cara mengadakan wawancara (interview) dengan para responden atau informan. Dalam mendapatkan data yang diperlukan, dgunakan metode wawancara bebas terpimpin yang bersifat komprehensif (mendalam) (Ashshofa, 2004), sesuai bahasapenulis tentang pengembangan budidaya pertanian sebagai upaya peningkatan penanaman modal.

\section{Analisis}

Setelah data yang dibutuhkan terkumpul, data tersebut akan diolah dan dianalisis dengan menggunakan metode pengolahan data secara sistematis, yaitu dengan argumentasi hukum berdasarkan logika deduktif dan iduktif. Proses penyajiannya dilakukan secara deskriptif analisis.

\section{HASIL DAN PEMBAHASAN}

Perangkat Peraturan Perundang-Undangan dalam Pengembangan Kawasan Budidaya Pertanian

Sebagian besar pekerjaan yang digeluti masyarakat Buleleng bergerak di sektor pertanian dalam arti luas (pertanian tanaman pangan, perkebunan, perternakan, dan perikanan) sehingga Kabupaten Buleleng disebut sebagai daerah agraris (BAPPEDA Buleleng, 2015). Istilah agraris sering dikaitkan dengan corak kehidupan masyarakat atau bangsa, seperti halnya Indonesia sebagai negara agraris, yaitu suatu bangsa yang besar populasi masyarakatnya hidup dari bercocok tanam (bertani) atau sebagian penghasilan masyarakatnya diperoleh dari sektor pertanian .

UU No. 5 Tahun 1960 pada Konsideran Menimbang huruf a dijelaskan "bahwa Negara Republik Indonesia yang susunan kehidupan rakyatnya, termasuk perekonomiannya, terutama bercorak agraris, 
bumi, air, dan ruang angkasa sebagai karunia Tuhan Yang Maha Esa memiliki fungsi yang amat penting untuk membangun masyarakat yang adil dan makmur."

Sektor pertanian dalam arti luas berkaitan erat dengan bumi, air, ruang angkasa, dan kekayaan alam yang terkandung di dalamnya memiliki korelasi dengan skripsi ini, bumi, air, ruang angkasa, dan kekayaan alam yang terkandung di dalamnya yang berada pada wilayah Kabupaten Buleleng. Agar dapat memberikan manfaat yang besar kepada masyarakat khususnya di Kabupaten Buleleng maka wilayahwilayah terkait sektor budidaya pertanian harus dikembangkan. Sehingga memerlukan pengaturan dalam pemanfaatannya. UUPA memiliki keterkaitan yang erat dengan UU No. 26 Tahun 2002 tentang Penataan Ruang, seperti halnya termuat dalam Pasal 1 angka 1 yang membagi ruang atas beberapa wilayah, meliputi ruang darat, ruang laut, dan ruang udara (Santoso, 1991).

Masyarakat Buleleng secara mandiri telah mengusahakan sektor pertanian dalam arti luas tentu dengan sekala yang kecil di masing-masing tempat tinggalnya (Sutawa, 2012; Statistik Kabupaten Buleleng, 2018). Upaya untuk memberikan hasil yang lebih memadai, maka perlu campur tangan Pemerintah Daerah, sebagai upaya pengembangan, dengan dimungkinkan pemanfaatan teknologi (teknologi tepat guna) (Patera dkk., 2015). Campur tangan terebut terkait pengembangan kawasan budidaya pertanian sehingga memberikan manfaat atau nilai tambah (valued added) bagi peningkatan kesejahteraan masyarakat.

Oleh karenanya dibutuhkan penanam modal atau investor baik nasional maupun asing agar mau menanamkan modalnya di wilayah Indonesia. Maka perlu adanya kebijakan-kebijakan pemerintah yang dapat memikat investor, salah satu upaya yang dapat dilaksanakan dengan memberikan kemudahan kepada investor dengan upaya menyediakan lokasi budidaya yang siap pakai, meliputi lahan yang siap, adanya jaminan hak atas tanah, tersedianya sarana dan prasarana, kemudahan dalam memperoleh izin. Disamping itu diperlukan suasana atau keadaan yang kondusif, sehingga faktor kenyamanan, keamanan, dan ketentraman bagi investor mutlak diperuntukan.

Adanya UU No. 23 Tahun 2014 tentang Pemerintahan Daerah, dapat memberikan kesempatan bagi Pemerintah Daerah untuk menyediakan lokasi kawasan budidaya pertanian yang dapat digunakan sebagai sarana untuk memberikan kemudahan bagi investor untuk menanamkan modal di daerahnya. Pada Pasal 176 menyatakan bahwa Pemerintah Daerah dalam meningkatkan perekonomian dapat memberikan insentif dan/atau kemudahan kepada masyarakat atau investor (Statistik Kabupaten Buleleng, 2018). Adanya investor dapat berkontribusi dalam peningkatan ekonomi daerah. Jika halnya Kabupaten Buleleng dapat memberikan kemudahan dan menyediakan fasilitas yang dibutuhkan investor, maka akan memberikan peluang bagi Kabupaten Buleleng untuk unggul dalam memikat investor, dan berimbas pada sumber pendapatan daerah yang dapat ditingkatkan sehingga mencapai kemandirian daerah.

\section{Pelaksanaan Pembangunan Kawasan Budidaya Pertanian di Kabupaten Buleleng}

Pemerintah telah mengeluarkan regulasi berupa undang-undang, yaitu UU No. 12 Tahun 1992 tentang Sistem Budidaya Tanaman, adanya tuntutan reformasi menjadikan UU No. 12 Tahun 1992 digantikan oleh UU No. 22 Tahun 2019 tentang Sistem Budidaya Pertanian Berkelanjutan. Tujuan sistem budidaya berkelanjutan untuk meningkatkan penganekaragaman hasil pertanian, guna memenuhi kebutuhan pangan, sandang, papan, kesehatan, industri dalam negeri, dan memperbesar ekspor, meningkatan pendapatan dan taraf hidup petani serta mendorong perluasan dan pemerataan kesempatan berusaha dan kesempatan kerja.

Sistem budidaya berkelanjutan dilaksanakan dengan mempertimbangkan daya dukung ekosistem, mitigasi dan adabtasi perubahan iklim, serta kelestarian lingkungan demi upaya mewujudkan sistem pertanian yang maju, efisien, tangguh dan berkelanjutan (Sutawa, 2012; Januarsa \& Luthfi, 2017) Teori ekstensifikasi dan intensifikasi perlu di implementasikan dalam penyelenggaraan budadaya ini. ekstensifikasi dimaksudkan untuk memperluas areal atau lahan budidaya, di mana hal ini sulit untuk diterapkan karena lahan yang sudah ada tidak mungkin bertambah, justru semakin tergerus (berkurang) karena berbagai faktor. Sedangkan intensifikasi diarahkan pada intensifikasi usaha budidaya dengan menerapkan teknologi tepat guna, sebagai rencana perolehan panen budidaya pertanian dapat meningkat dan berkelanjutan.

Berbagai hambatan ditemui dalam penyelenggaraan pengembangan kawasan budidaya pertanian, diantaranya : 
1) Penambahan luasan kawasan

Kawasan yang dimaksud adalah areal yang akan dipergunakan untuk penyelenggaraan budidaya pertanian dalam arti luas. Penembahan luasan kawasan berarti mengalokasikan wilayah lain untuk dapat dipergunakan sebagai wilayah budidaya. Karena sulit dan terkendalanya penambahan luasan kawasan, solusi yang dapat dilaksanakan dengan intensifikasi dalam pengelolaan lahan budidaya, dengan diterapkannya teknologi pertanian tepat guna, mulai dari pengelolaan tanah, penyiapan bibit/benih, pemupukan, pelaksanaan panen, dan pemasaran.

2) Penjagaan kelestarian lingkungan

Lahan yang memadai dibutuhkan dalam penyelenggaran budidaya pertanian, sehingga perlu ada yang dikorbankan termasuk kelestarian lingkungan, awal mulanya hijau pepohonan akibat dari pembabatan berubah fungsi sebagai lahan untuk ditanami tanaman pertanian yang dibudidayakan.

3) Terjadinya alih fungsi lahan

Kawasan budidaya pertananian tidak dapat dikembangkan dan ditambah luasnya, akan tetapi luasnya semakin berkurang akibat pembanguan. Sehingga terjadi alih fungsi lahan yang pada awalnya lahan pertanian, berubah menjadi perumahan dan perkantoran, alih fungsi lahan disebabkan pertambahan jumlah penduduk yang tinggi.

4) Dukungan sumber daya alam

Sumber air merupakan komuditi yang penting dalam penyelenggaran budidaya pertanian, namun setiap wilayah yang berada pada Kabupaten Buleleng tidak seluruhnya di aliri oleh sumber air yang memadai dan mencukupi kebutuhan dan keseterdiaan sepanjang tahun.

\section{SIMPULAN DAN SARAN}

\section{Simpulan}

Pelaksanaan pengembangan kawasan pertanian sudah didasarkan pada aturan perundang-undangan yang berlaku, dan mengacu pada Peraturan Daerah Kabupaten Buleleng No. 9 Tahun 2013 tentang Rencana Tata Ruang Wilayah (RTRW) Kabupaten Buleleng Tahun 2013 - 2033. Masih adanya hambatan yang menjadi kendala proses pembangunan berkelanjutan, berupa luasan kawasan budidaya pertanian, pemeliharaan kelestarian lingkungan, terjadinya alih fungsi lahan, dan sumber daya alam terkait penyediaan sumbar daya air yang berkecukupan.

\section{Saran}

Untuk meningkatan hasil dan daya guna kawasan budidaya pertanian di Kabupaten Buleleng, disarankan hal-hal beberapa hal. Pertama, penyelenggaraan atau pemeliharaan kawasan lingkungan wajib mendapatkan perhatian penuh dari pemerintah daerah maupun masyarakat, oleh karena kelestarian lingkungan merupakan prasyarat pembangunan kawasan budidaya pertanian; kedua, Partisipasi masyarakat juga merupakan faktor terpenting dalam keberhasilan pembangunan kawasan budidaya pertanian; dan ketiga Upaya menarik minat investor harus terus digalangkan dengan berbagai cara agar dapat memberikan penyediaan dana, bantuan menejemen, dan pengembangan SDM secara berkelanjutan.

\section{DAFTAR PUSTAKA}

Ashshofa, B. (2004). Metode Penelitian Hukum. Rineka Cipta.

BAPPEDA Buleleng. (2015). Profil Investasi Kabupaten Buleleng.

Beeton, S. (2006). Community Development through Tourism. In Community Development through Tourism (Issue January). Landlinks Press. https://doi.org/10.1071/9780643093881

Ciolac, R., Adamov, T., Iancu, T., Popescu, G., Lile, R., Rujescu, C., \& Marin, D. (2019). AgritourismA Sustainable Development Factor for Improving the "Health" of Rural Settlements. Case Study Apuseni Mountains area. Sustainability (Switzerland), 11(5). https://doi.org/10.3390/su11051467

Januarsa, I. N., \& Luthfi, O. M. (2017). Community Based Coastal Conservation in Buleleng. ECSOFiM: Economic and Social of Fisheries and Marine Journal, 04(02), 166-173.

Kantor Perwakilan Bank Indonesia Provinsi Bali. (2019). Kajian Ekonomi dan Keuangan Regional Provinsi Bali. Bank Indonesia.

Kementerian PPN/Bappenas. (2018). Perkembangan Ekonomi Indonesia dan Dunia. In Journal of Petrology (Vol. 2, Issue 1). Kedeputian Bidang Ekonomi Kementerian PPN/Bappenas. 
https://doi.org/10.1017/CBO9781107415324.004

Patera, I. M., Sukarsa, M., \& Wiranatha, A. . S. (2015). Effect of Tourism and Economic Performance on Poverty in Bali. International Journal of Multidisciplinary Educational Research, 4(12), 17-53. https://doi.org/10.4324/9781351169448-2

Praktiknya. (2007). Pengembangan Kawasan Industri Dalam Meningkatkan Investasi. Universitas Diponegoro.

Santoso, U. (1991). Pendaftaran dan Peralihan Hak atas Tanah. Predana Media.

Statistik Kabupaten Buleleng. (2018). Tinjauan Perkembangan Ekonomi Kabupaten Buleleng. In Singa Ambara Raja (Vol. 53, Issue 9). https://doi.org/10.1017/CBO9781107415324.004

Sutawa, G. K. (2012). Issues on Bali Tourism Development and Community Empowerment to Support Sustainable Tourism Development. Procedia Economics and Finance, 4(Icsmed), 413-422. https://doi.org/10.1016/s2212-5671(12)00356-5

Tulusan, F. M. G., \& Londa, V. Y. (2014). Peningkatan Pendapatan Masyarakat Melalui Program Pemberdayaan di Desa Lolah II Kecamatan Tombariri Kabupaten Minahasa. Jurnal LPPM Bidang EkoSosBudKum, 1(1), 92-105.

Yudyawati, A., \& Koman, L. (2015). Pengaturan Peraturan Daerah Provinsi Bali Nomor 5 Tahun 2009 terhadap Penanam Modal di Bali. Universitas Warmadewa.

Yuendini, E. P., Rachmi, I. N., Nurul, N., Puspitasari, A., \& Harini, R. (2019). Analisis Potensi Ekonomi Sektor Pertanian dan Sektor Pariwisata di Provinsi Bali Menggunakan Teknik Analisis Regional. Jurnal Geografi, 16(2), 128-136. https://doi.org/10.15294/jg.v16i2.20831 